\title{
TWO-PARAMETER SUNOUCHI OPERATOR WITH RESPECT TO CHARACTER SYSTEM OF $p$-SERIES FIELD IN THE KACZMARZ REARRANGEMENT
}

\author{
ChuAnZhou Zhang AND XUEying Zhang
}

Abstract. Let $G_{p}$ be $p$-series field. We prove the restricted two-parameter Sunouchi operator $T_{h}^{\chi}$ is bounded from $H_{q}^{\square}$ to $L_{q}$ for $0<q \leqslant 1$. By means of interpolation and duality argument, this theorem can be extended to Hardy-Lorentz spaces. As a consequence, we prove the restricted Sunouchi operator is of weak type $\left(L_{1}, L_{1}\right)$.

Mathematics subject classification (2010): 42C10.

Keywords and phrases: Character system, Kaczmarz rearrangement, Sunouchi operator.

\section{REFERENCES}

[1] G.-I. Sunouchi, On the Walsh-Kaczmarz series, Proc. Amer. Math. Soc. 2 (1951), 5-11.

[2] G.-I. SunouchI, Strong summability of Walsh-Fourier series, Tohoku Math. J. 16 (1969), 228-237.

[3] P. Simon, $\left(L^{1}, H\right)$-type estimations for some operators with respect to the Walsh-Paley system, Acta Math. Hungar. 46 (1985), 307-310.

[4] F. WeIsZ, The boundedness of the two-parameter Sunouchi operators on Hardy space, Acta Math. Hungar. 72, 1-2 (1996), 121-132.

[5] G. GÁT, Investigation of some operators with respect to Vilenkin systems, Acta Math. Hungar. 61 (1993), 131-144.

[6] G. GÁt, On the lower bound of Sunouchi's operator with respect to Vilenkin system, Analysis Math. 23 (1997), 259-272.

[7] P. Simon, Investigation with respect to Vilenkin systems, Ann. Univ. SciBudapest. Sect. Math. 27 (1982), 87-101.

[8] P. Simon, A note on the Sunouchi operator with respect to the Vilenkin system, Ann. Univ. SciBudapest. Sect. Math. 43 (2000), 101-116.

[9] G. GÁt, Investigation of the Sunouchi operator with respect to the Walsh-Kaczmarz system, Acta Math.Hungar. 89, 1-2 (2000), 93-101.

[10] G. GÁt, Orthonormal systems on Vilenkin groups, Acta Math. Hungar. 58, 1-2 ( 1991), 193-198.

[11] F. Schipp, W. R. WAde, P. Simon, AND J. PÁL, Walsh Series: An introduction to dyadic harmonic analysis, Adam Hilger (Bristol-New York ,1990).

[12] N. YA. VilenKIn, On a class of complete orthonormal systems, Izd. Akad. Nauk SSSR. 11 (1947), 363-400(in Russian).

[13] D. L. BURKhOlDer, Distribution function inequalities for martingales, Annals of Prob. 1 (1973), $19-42$.

[14] D. L. BURKHOLDER AND R. F. GUNDY, Extrapolation and interpolation of quasi-linear operators on martingales, Acta Math.Hungar. 124 (1970), 249-304.

[15] B. J. DAVIS, On the integrability of the martingale square function, Israel J.Math. 8 (1970), 187-190.

[16] J. BRossard, Comparaison des "normes" $L_{p}$ du processus croissant et de la variable maximale pour les martingales régulières à deux indices, Théorème local correspondant 8 (1980), 1183-1188.

[17] J. Brossard, Régulaité des martingales à deux in dicies et inégalités de normes, Processus Aléatoires à Deux Indices, Lect. Notes Math., vol. 863, Springer (Berlin, Heidelberg, New York, 1981), pp. 91-121. 
[18] C. MetrauX, quelques inégalités pour martingales à parametre bidimensional, Séminaire de Probalitiés XII, Lect. Notes., vol. 649, Springer (Berlin, Heidelberg, New York, 1978), pp. 170-179.

[19] J. Neveu, Discrete-parameter Martingale, Nort-Holland, 1971.

[20] R. CAIRoLI, Unégalité pour martingale à indices multiples et res applications, Séminaire de Probalitiés IV, Lect. Notes., vol. 124, Springer (Berlin, Heidelberg, New York, 1970), pp. 1-27.

[21] F. MóRICZ, F. SCHIPP AND W. R. WADE, Cesàro summability of double Walsh-Fourier series, Trans. Amer. Math. Soc. 329 (1992), 131-140.

[22] G. GÁt AND K. NAGY, Cesàro summability of the character system of the p-series field in the Kaczmarz rearrangement, Analysis. Math. 28 (2002), 1-23.

[23] U. GoginaVA, The maximal operator of the Fejér means of the character system of the p-series field in the Kaczmarz rearrangement, Publ. Math. Debrecen 3576 (2006), 1-15.

[24] F. WeIsz, Martingale Hardy spaces and their Applications in Fourier-Analysis, Lecture Notes in Math. vol 1568, Springer (Berlin, Heidelberg, New York, 1994).

[25] C. Z. Zhang AND X. Y. Zhang, Sunouchi operator of the Character System of the p-series Field in the Kaczmarz Rearrangement, Advances In Mathematics (China) 39, 2 (2010), 151-158.

[26] F. WeIsz, Cesàro summability of two-dimensional Walsh-Fourier series, Trans. Math. Soc. 348 (1996), 2169-2181. 